\title{
(6) OPEN ACCESS \\ Developmental trajectories of Body Mass Index from infancy to 18 years of age: prenatal determinants and health consequences
}

\author{
Ali H Ziyab, ${ }^{1,2}$ Wilfried Karmaus, ${ }^{3}$ Ramesh J Kurukulaaratchy, ${ }^{4}$ Hongmei Zhang, ${ }^{3}$ \\ Syed Hasan Arshad ${ }^{4,5}$
}

- Additional material is published online only. To view please visit the journal online (http://dx.doi.org/10.1136/jech2014-203808)

${ }^{1}$ Department of Epidemiology and Biostatistics, Norman J. Arnold School of Public Health, University of South Carolina, Columbia, South Carolina, USA

${ }^{2}$ Department of Community Medicine and Behavioral Sciences, Faculty of Medicine, Kuwait University, Kuwait ${ }^{3}$ Division of Epidemiology, Biostatistics, and Environmental Health, School of Public Health, University of Memphis, Memphis, Tennessee, USA ${ }^{4}$ David Hide Asthma and Allergy Research Centre, Isle of Wight, UK

${ }^{5}$ Academic Unit of Clinical and Experimental Medicine, Faculty of Medicine, University of Southampton, Southampton, UK

\section{Correspondence to} Professor Wilfried Karmaus, Division of Epidemiology, Biostatistics, and Environmental Health, School of Public Health, University of Memphis, 301 Robison Hall, Memphis, TN 38152, USA; karmaus1@memphis.edu

Received 5 January 2014 Revised 14 May 2014 Accepted 15 May 2014 Published Online First 3 June 2014
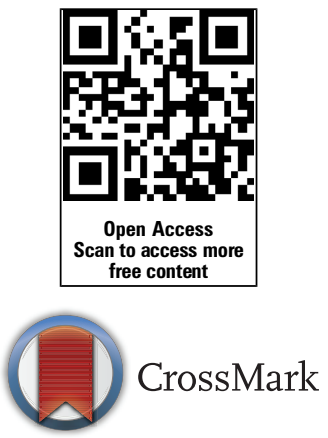

To cite: Ziyab $\mathrm{AH}$

Karmaus W,

Kurukulaaratchy RJ, et al. J Epidemiol Community Health 2014;68:934-941.

\section{ABSTRACT}

Background Knowledge on the long-term development of adiposity throughout childhood/ adolescence and its prenatal determinants and health sequelae is lacking. We sought to (1) identify trajectories of Body Mass Index (BMI) from 1 to 18 years of age, (2) examine associations of maternal gestational smoking and early pregnancy overweight with offspring BMI trajectories and (3) determine whether BMI trajectories predict health outcomes: asthma, lung function parameters (forced expiratory volume in one second $\left(\mathrm{FEV} \mathrm{F}_{1}\right) /$ forced vital capacity (FVC) ratio), and blood pressure, at 18 years.

Methods The Isle of Wight birth cohort, a populationbased sample of 1456 infants born between January 1989 and February 1990, was prospectively assessed at ages 1, 2, 4, 10 and 18 years. Group-based trajectory modelling was applied to test for the presence of latent BMI trajectories. Associations were assessed using logbinomial and linear regression models.

Results Four trajectories of BMI were identified: 'normal', 'early persistent obesity', 'delayed overweight', and 'early transient overweight'. Risk factors for being in the early persistent obesity trajectory included maternal smoking during pregnancy (RR 2.16, 95\% Cl 1.02 to 4.68) and early pregnancy overweight $(3.16,1.52$ to 6.58). When comparing the early persistent obesity to the normal trajectory, a 2.15-fold (1.33 to 3.49) increased risk of asthma, $3.2 \%$ ( $0.4 \%$ to $6.0 \%)$ deficit in $\mathrm{FEV}_{1} / \mathrm{FVC}$ ratio, and elevated systolic $11.3 \mathrm{~mm} \mathrm{Hg}$ (7.1 to 15.4 ) and diastolic $12.0 \mathrm{~mm} \mathrm{Hg}$ (8.9 to 15.1 ) blood pressure were observed at age 18 years.

Conclusions Maternal prenatal exposures show prolonged effects on offspring's propensity towards overweight-obesity. Distinct morbid BMI trajectories are evident during the first 18 years of life that are associated with higher risk of asthma, reduced $\mathrm{FEV}_{1} / \mathrm{FVC}$ ratio, and elevated blood pressure.

\section{INTRODUCTION}

The burden of obesity and being overweight has reached epidemic levels globally by affecting more than 1.5 billion adults and accounting for $0.7 \%$ to $2.8 \%$ of healthcare expenditures worldwide. ${ }^{1} 2$ Particularly concerning is the increase in childhood and adolescence overweight obesity, which is a predictor of adulthood obesity, morbidity and mortality. ${ }^{3}{ }^{4}$ A survey in English schoolchildren found that $22.6 \%$ and $33.9 \%$ of ' 4 and 5 ' and ' 10 and 11 ' year old children, respectively, are obese or overweight, ${ }^{5}$ suggesting that obesity may have its origins in early life.
Multiple prenatal exposures have been associated with increased risk of subsequent overweight obesity among exposed offspring. ${ }^{6}{ }^{7}$ Maternal smoking during pregnancy and prepregnancy/early pregnancy adiposity have demonstrated consistent associations with single measurements of childhood and adolescence overweight and obesity, ${ }^{8-11}$ but their effects on the long-term development of adiposity are unknown. The consequences of early life overweight obesity are highlighted by earlier expression of parameters associated with adult conditions like cardiovascular disease. ${ }^{12} 13$ Meanwhile, conflicting associations of overweight obesity with childhood asthma and lung function have been reported; with more positive findings emerging for asthma, ${ }^{14} 15$ but no replicated associations reported for lung function parameters among children/ adolescents. ${ }^{16}$

A pragmatic challenge of many past studies is that Body Mass Index ((BMI); an indicator of obesity and overweight) is assessed at one point in time. This static assessment ignores the dynamics of BMI over time and may misdirect etiologic research. In addition to the 'intensity' of adiposity, simultaneously considering 'duration' plus 'intensity' may improve predictive value and unveil greater effects of BMI on health-related outcomes. Obesity-years, a recently developed measure accounting for duration and intensity of obesity ${ }^{17}$ is associated with elevated morbidity and mortality. ${ }^{16}{ }^{18-20}$ One promising approach overcoming limitations of static analyses is to identify developmental BMI trajectories and their risk factors. A trajectory is defined as established sequences of transitions from one state or phenotype to another, describing its evolution over time. ${ }^{21}$ Identifying BMI trajectories, that is groups of individuals following similar developmental patterns of BMI over age, ${ }^{22}$ provides three integral pieces of information on the developmental patterns of adiposity: 'age-of-onset', 'duration' and 'intensity'. A limited number of longitudinal studies have identified developmental trajectories of BMI in childhood and/or adolescence (see online supplementary table S1). ${ }^{23-30}$ Of these eight studies, only two prospectively covered childhood and adolescence periods, but neither of these included early childhood. ${ }^{25} 30$

Given the potential importance of prenatal influences on childhood overweight obesity, there is a need to extend our understanding to BMI trajectories that commence in infancy. Using data from the Isle of Wight birth cohort, covering infancy to late adolescence (18 years), we sought to (1) identify 
distinct BMI trajectories, (2) examine associations of maternal gestational smoking and early pregnancy overweight with offspring BMI trajectories and (3) determine whether BMI trajectories predict health outcomes including asthma, forced expiratory volume in one second $\left(\mathrm{FEV}_{1}\right)$ to forced vital capacity (FVC) ratio, and blood pressure, at 18 years of age.

\section{METHODS}

\section{Setting and participants}

The Isle of Wight birth cohort, an unselected population-based study, was recruited between January 1989 and February 1990 in the Isle of Wight, UK, to study the natural history and aetiology of asthma and allergic diseases. After excluding adoptions, perinatal deaths, and refusals for follow-up, 1456 children (95\%) were enrolled, with follow-up assessments conducted at 1 (5th-95th percentile: 0.8-1.1), 2 (1.7-2.3), 4 (3.9-4.4), 10 (9.7-10.3), and 18 (17.6-18.5) years of age. Ethics approvals were obtained from the Isle of Wight Local Research Ethics Committee at recruitment and for subsequent follow-ups (06/Q1701/34). Written informed consent was obtained from parents, participants, or both. In our analysis we included participants who had two or more measurements of height and weight across the follow-ups. Of the original cohort, 1240 $(85.2 \%)$ participants satisfied our inclusion criteria.

\section{Anthropometric measures}

Height and weight were directly measured during follow-up visits in the research centre $(100 \%$ at ages 1,2 , and $4,99.8 \%$ $(1020 / 1022)$ at age 10 , and $90.2 \%(841 / 932)$ at age 18 years) or self-reported when a visit was not possible. BMI was calculated as weight in kilograms divided by height in meters squared. An increase in BMI during early life is a feature of natural growth. To increase comparability across ages, we calculated individual BMI z-scores (SD scores) based on age-specific averages in the birth cohort. The terms 'overweight' and 'obesity' in this article comply with the age-specific thresholds of BMI proposed by the International Obesity Taskforce $(\mathrm{IOTF})^{31}$ for ages 4,10 and 18 years, and WHO standards for age 1 year. $^{32}$

\section{Prenatal maternal characteristics}

Maternal smoking during pregnancy and early pregnancy overweight were considered as prenatal risk factors for offspring BMI trajectories. Information on maternal smoking during pregnancy was ascertained soon after birth of the child. Records of measured height and weight at antenatal visit were obtained and used to calculate maternal early pregnancy BMI. We dichotomised maternal early pregnancy BMI as normal (BMI <25.0) and overweight (BMI $\geq 25.0$ ). The underweight (BMI <18.5) group was analysed with the normal group due to a small proportion $(1.8 \%)$ of mothers being underweight. Similarly, due to a limited number $(n=86,8.9 \%)$ of mothers being obese (BMI $\geq 30$ ), we analysed maternal overweight and obesity as one group.

\section{Health outcomes at 18 years of age}

We tested whether BMI trajectories are predictors of asthma, $\mathrm{FEV}_{1} / \mathrm{FVC}$ ratio, and blood pressure at age 18 years. Asthma was defined as a history of physician-diagnosed asthma plus at least one episode of wheezing or asthma treatment in the previous 12 months, using the International Study of Asthma and Allergies in Childhood questionnaire. ${ }^{33}$ Pulmonary function tests, measuring FVC and $\mathrm{FEV}_{1}$, were performed using a Koko Spirometer and software with a desktop portable device (PDS
Instrumentation, Louisville, Colorado, USA), according to American Thoracic Society guidelines. ${ }^{34}$ During the 18 years follow-up, blood pressure was measured in a rested and seated position, with the appropriate cuff size, by a trained study nurse using an aneroid sphygmomanometer.

\section{Confounders}

Adjustments for potential confounders were carried out based on prior knowledge in published literature and plausible direct/ indirect association with the outcome variable. Information on child's sex, birth weight, gestational age at birth, maternal age at delivery, and maternal education was collected soon after birth. Information on duration of breastfeeding was obtained at the 1 and/or 2 years follow-ups. Socioeconomic status is a composite variable that captures the family social class across the first 10 years of life (see online methods I for more details on confounders).

\section{Statistical analysis}

\section{Determining BMI z-score trajectories}

A group-based trajectory modelling, also referred to as a semiparametric mixture model, ${ }^{35}$ was applied using PROC TRAJ macro in SAS to identify BMI z-score developmental trajectories across ages $1,4,10$ and 18 years. ${ }^{36}$ To ensure that early childhood BMI is not overweighted in the developmental trajectories, the follow-up at 2 years of age was not included in the determination of BMI z-score trajectories. The group-based trajectory method presumes that the data comprises latent distinct groups (trajectories) that best summarise the complex developmental information collected over a life-course. ${ }^{22}$ We followed the general recommendations of selecting the model with smallest absolute Bayesian Information Criterion value that also minimises overlap in the CIs of adjacent trajectories while summarising the distinctive features of the data in a fashion as parsimonious as possible. ${ }^{22} 35$ Models were estimated with two to six groups (see online supplementary figure S1) while testing parameter estimates for linear and quadratic terms. The previous exploratory steps were performed for boys and girls separately and in combination. After selecting the best fitting model, individuals were assigned to one of the trajectories/groups based on their highest estimated group-membership probabilities. This categorical variable was used in all subsequent analyses. To further assess model adequacy, we ensured that the average of group-membership probabilities for individuals in each trajectory/group exceeded a threshold of $0.7 .^{22}$

\section{Descriptive and association analyses}

All statistical analyses were conducted using SAS V.9.3 (SAS Institute, Cary, North Carolina, USA). The statistical significance level was set to $\alpha=0.05$ for all association analyses. To assess whether the analytical sample $(n=1240)$ was representative of the total cohort $(n=1456)$, we compared proportions of categorical variables (using $\chi^{2}$ tests) and means of continuous variables (using t tests) across these two samples. Average weight gain per year across different developmental intervals (birth to 1, 1-4, 4-10, and 10-18 years) was estimated for each of the identified BMI z-score trajectories. Risk ratios (RR) and their associated 95\% CIs were calculated using log-binomial regression, which was applied to estimate associations between maternal prenatal characteristics (predictors) and BMI trajectories (outcome variable; 'normal' trajectory formed the reference category). Two models were tested: the first model only adjusted for sex, whereas, the second model controlled for the following potential confounders: birth weight, gestational age at birth, 
maternal age at delivery, duration of breastfeeding, maternal education, and socioeconomic status. Multivariable linear regression was used to determine the association between BMI trajectories (predictors) and health outcomes measured on a continuous scale at age 18 years. Log-binomial regression was used when asthma was the outcome variable.

\section{Sensitivity analysis}

To explore whether including participants who self-reported their anthropometric measurements $(n=2$ at age 10 and $n=91$ at age 18 years) could have biased our findings, we repeated our analyses excluding the 93 participants who self-reported their measurements. Additionally, we controlled for concurrent BMI while assessing the association of BMI trajectories with health outcomes at age 18 years.

\section{RESULTS}

\section{Description of study sample}

The analysed sample $(n=1240)$ and the total cohort $(n=1456)$ were similar with respect to all characteristics under study (table 1), indicating that a restriction on participants with $\geq 2$ repeated BMI measurements did not result in obvious selection bias. Of the analytical sample, BMI measurements at ages 1, 4, 10 and 18 years were available for 967 (78\%), 1022 (82\%), 1022 (82\%) and 932 (75\%) participants, respectively. Maternal BMI was measured, on average, during the 14 th $( \pm 4)$ week of gestation.

\section{BMI z-score trajectories}

In an exploratory step, we determined the trajectories separately for boys and girls to decide whether both sexes followed similar

Table 1 Characteristics of enrolled participant children and children included in the analysis

\begin{tabular}{|c|c|c|}
\hline & $\begin{array}{l}\text { Enrolled study } \\
\text { sample }(n=1456)\end{array}$ & $\begin{array}{l}\text { Analytical study } \\
\text { sample }(n=1240)\end{array}$ \\
\hline \multicolumn{3}{|l|}{ Sex, n (\%) } \\
\hline Male & $745(51.2)$ & $626(50.5)$ \\
\hline Female & $711(48.8)$ & $614(49.5)$ \\
\hline \multicolumn{3}{|c|}{ Maternal smoking during pregnancy, $n(\%)$} \\
\hline No & $1078(74.8)$ & $959(77.5)$ \\
\hline Yes & $364(25.2)$ & $278(22.5)$ \\
\hline Missing, $n$ & 14 & 3 \\
\hline \multicolumn{3}{|c|}{ Maternal early pregnancy BMI $\left(\mathrm{kg} / \mathrm{m}^{2}\right), \mathrm{n}(\%)$} \\
\hline$<25.0$ & $760(64.7)$ & $637(66.0)$ \\
\hline$\geq 25.0$ & $415(35.3)$ & $328(34.0)$ \\
\hline Missing, $n$ & 281 & 275 \\
\hline \multicolumn{3}{|l|}{ Asthma at age 18 years, $\mathrm{n}(\%)$} \\
\hline No & $1074(82.3)$ & $937(82.1)$ \\
\hline Yes & $231(17.7)$ & $204(17.9)$ \\
\hline Missing, $n$ & 151 & 99 \\
\hline $\begin{array}{l}\mathrm{FEV}_{1} / \mathrm{FVC} \% \text { at age } 18 \text { years, } \\
\text { Mean (SD) }\end{array}$ & $87.3(7.2)$ & $87.3(7.2)$ \\
\hline Missing, $n$ & 617 & 416 \\
\hline $\begin{array}{l}\text { Systolic blood pressure at age } \\
18 \text { years, Mean (SD) }\end{array}$ & $108.6(11.9)$ & $108.5(11.9)$ \\
\hline Missing, $n$ & 608 & 409 \\
\hline $\begin{array}{l}\text { Diastolic blood pressure at } \\
\text { age } 18 \text { years, Mean (SD) }\end{array}$ & $64.7(9.1)$ & $64.7(9.1)$ \\
\hline Missing, $\mathrm{n}$ & 608 & 409 \\
\hline
\end{tabular}

trajectories. In agreement with previous reports (see online supplementary table S1), we identified four trajectories in both sexes that were similar in their developmental patterns, but differed in their proportions. Thus, BMI z-score trajectories were combined and we controlled for the effect of sex in the multivariable models.

The four distinct trajectories that best characterised the complex developmental course of BMI z-score across the first 18 years of life in the IOW study population are shown in figure 1 . The trajectories were labelled as 'normal' $(71.5 \% ; \mathrm{n}=886)$, 'early persistent obesity' $(3.9 \% ; n=48)$, 'delayed overweight' $(11.5 \% ; n=143)$, and 'early transient overweight' $(13.1 \% ; n=163)$. Descriptive statistics of these four trajectories are provided in table 2. At ages 4, 10 and 18 years, the mean BMI of the early persistent obesity trajectory exceeded the age-specific obesity cut-offs suggested by the IOTF. $^{31}$ The delayed overweight trajectory crossed the age-specific overweight thresholds at ages 10 and 18 years in regard to their mean BMI. The mean BMI of the early transient overweight trajectory was higher than the age-specific overweight cut-off suggested by the $\mathrm{WHO}^{32}$ only at 1 year of age. Furthermore, average weight gain per year was estimated for each of the four trajectories across different developmental time-windows (see online supplementary figure S2 and online results I).

\section{Prenatal predictors of BMI z-score trajectories}

Associations between maternal smoking during pregnancy and early pregnancy overweight (BMI $\geq 25$ ) with offspring BMI $\mathrm{Z}$-score trajectories are presented in table 3. The 'normal' BMI $\mathrm{z}$-score trajectory was considered as reference group. In the sexadjusted model and the model adjusted for potential confounders, maternal smoking during pregnancy and early pregnancy overweight were associated with increased risk of being in the 'early persistent obesity' and 'delayed overweight' trajectories (table 3). Maternal smoking during pregnancy showed higher risk $(\mathrm{RR}=2.16,95 \% \mathrm{CI} 1.02$ to 4.68$)$ for the early persistent obesity trajectory in comparison to its association with the delayed overweight trajectory $(\mathrm{RR}=1.69,95 \% \mathrm{CI} 1.15$ to 2.49$)$. Similar patterns of associations between maternal early pregnancy overweight and BMI z-score trajectories were observed.

\section{BMI z-score trajectories as predictors of health outcomes at 18 years}

At 18 years of age, the risk of asthma was 2.15 -fold higher in the early persistent obesity trajectory as compared with the normal trajectory (table 4). Also, a 1.70-fold increased risk of

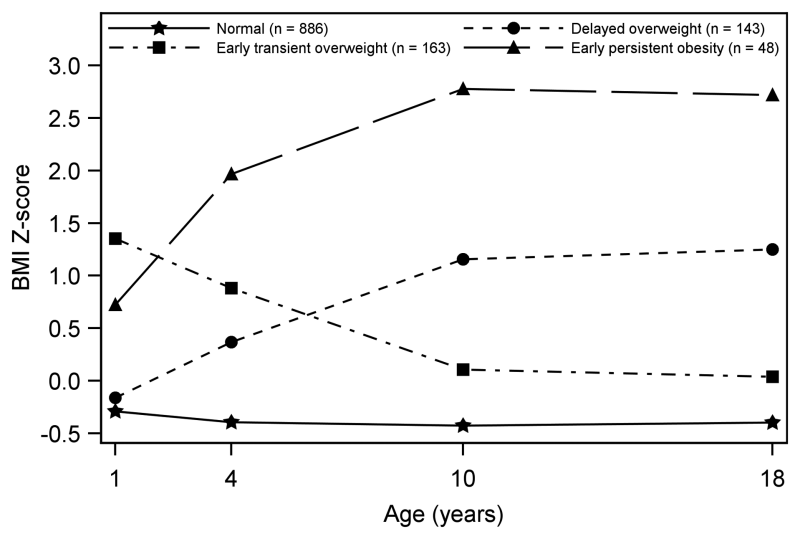

Figure 1 Trajectories of Body Mass Index z-score from 1 to 18 years of age. The four trajectories represent the latent growth patterns of body mass from 1 to 18 years of age. 
Table 2 Descriptive statistics of BMI z-score trajectories

\begin{tabular}{|c|c|c|c|c|}
\hline & \multicolumn{4}{|l|}{ BMI z-score trajectories } \\
\hline & Normal $(n=886)$ & Early persistent obesity $(n=48)$ & Delayed overweight $(n=143)$ & Early transient overweight $(n=163)$ \\
\hline \multicolumn{5}{|l|}{ Age 1 year } \\
\hline BMI & 16.9 (16.8 to 17.0$)$ & 18.5 (18.0 to 19.0$)$ & 17.1 (16.8 to 17.3$)$ & 19. 9 (19.6 to 20.2$)$ \\
\hline BMI z-score & $-0.28(-0.34$ to -0.22$)$ & 0.67 (0.37 to 0.97$)$ & $-0.20(-0.33$ to -0.06$)$ & $1.51(1.34$ to 1.67$)$ \\
\hline \multicolumn{5}{|l|}{ Age 4 years } \\
\hline BMI & 15.6 (15.5 to 15.7$)$ & 19.2 (18.7 to 19.7$)$ & $16.7(16.5$ to 16.9$)$ & 17.7 (17.5 to 17.9$)$ \\
\hline BMI z-score & $-0.38(-0.43$ to -0.33$)$ & 2.11 (1.73 to 2.46$)$ & $0.36(0.23$ to 0.48$)$ & $1.07(0.94$ to 1.19$)$ \\
\hline \multicolumn{5}{|l|}{ Age 10 years } \\
\hline BMI & 16.9 (16.7 to 17.0$)$ & 26.4 (25.5 to 27.4$)$ & 21.8 (21.4 to 22.1$)$ & 18.6 (18.2 to 18.9$)$ \\
\hline BMI z-score & $-0.42(-0.46$ to -0.38$)$ & 2.80 (2.48 to 3.12 ) & 1.23 (1.12 to 1.34$)$ & $0.15(0.04$ to 0.27$)$ \\
\hline \multicolumn{5}{|l|}{ Age 18 years } \\
\hline BMI & 21.5 (21.3 to 21.7$)$ & 34.9 (33.4 to 36.4$)$ & 29.0 (28.4 to 29.6$)$ & 23.5 (23.1 to 24.0$)$ \\
\hline BMI z-score & $-0.39(-0.44$ to -0.35$)$ & $2.70(2.35$ to 3.05$)$ & 1.35 (1.21 to 1.48$)$ & $0.07(-0.03$ to 0.18$)$ \\
\hline
\end{tabular}

All figures are presented as: Mean $(95 \% \mathrm{Cl})$.

BMI, Body Mass Index.

asthma was observed for the delayed overweight trajectory. By contrast, the early transient overweight trajectory was not associated with an elevated risk of asthma. The $\mathrm{FEV}_{1} / \mathrm{FVC}$ ratio was reduced by $3.2 \%$ and $1.7 \%$ among participants in the early persistent obesity and delayed overweight trajectories, respectively, in comparison to the normal trajectory (table 4). In regard to blood pressure, the early persistent obesity trajectory, on average, experienced higher systolic and diastolic blood pressure than the normal trajectory. Although the delayed overweight trajectory showed higher systolic and diastolic blood pressure than

Table 3 Associations of maternal smoking during pregnancy and maternal early pregnancy overweight (BMI $\geq 25.0)$ with offspring BMI z-score trajectories

\begin{tabular}{|c|c|c|c|c|}
\hline \multirow[b]{3}{*}{ BMI z-score trajectories } & \multicolumn{4}{|c|}{ Sex-adjusted model* } \\
\hline & \multicolumn{2}{|c|}{ Maternal smoking during pregnancy } & \multicolumn{2}{|c|}{ Maternal early pregnancy BMI $\left(\mathrm{kg} / \mathrm{m}^{2}\right)$} \\
\hline & No $(n=750)$ & Yes $(n=213)$ & $<25.0(n=636)$ & $\geq 25.0(n=327)$ \\
\hline Normal (Reference), $\mathrm{n}(\%)$ & $550(73.3)$ & $132(62.0)$ & $483(75.9)$ & $199(60.9)$ \\
\hline Early persistent obesity, $\mathrm{n}(\%)$ & $27(3.6)$ & $12(5.6)$ & $17(2.8)$ & $22(6.7)$ \\
\hline $\mathrm{RR}(95 \% \mathrm{Cl})$ & 1.00 & 1.83 (1.02 to 3.49$)$ & 1.00 & 2.84 (1.54 to 5.25$)$ \\
\hline $\mathrm{p}$ Value & & 0.044 & & $<0.001$ \\
\hline Delayed overweight, n (\%) & $80(10.7)$ & $34(16.0)$ & $53(8.3)$ & $61(18.7)$ \\
\hline RR $(95 \% \mathrm{Cl})$ & 1.00 & 1.61 (1.13 to 2.28$)$ & 1.00 & 2.32 (1.66 to 3.25$)$ \\
\hline$p$ Value & & 0.008 & & $<0.001$ \\
\hline Early transient overweight, $\mathrm{n}(\%)$ & $93(12.4)$ & $35(16.4)$ & $83(13.1)$ & $45(13.8)$ \\
\hline RR $(95 \% \mathrm{Cl})$ & 1.00 & 1.41 (0.93 to 2.01$)$ & 1.00 & 1.28 (0.92 to 1.77$)$ \\
\hline \multirow[t]{3}{*}{$\mathrm{p}$ Value } & & 0.076 & & 0.144 \\
\hline & \multicolumn{4}{|c|}{ Adjusted model $t$} \\
\hline & \multicolumn{2}{|c|}{ Maternal smoking during pregnancy } & \multicolumn{2}{|c|}{ Maternal early pregnancy BMI $\left(\mathrm{kg} / \mathrm{m}^{2}\right)$} \\
\hline BMI z-score trajectories & No $(n=657)$ & Yes $(n=164)$ & $<25.0(n=543)$ & $\geq 25.0(n=278)$ \\
\hline Normal (Reference), $\mathrm{n}(\%)$ & $474(72.2)$ & $100(61.0)$ & $409(75.3)$ & $165(59.4)$ \\
\hline Early persistent obesity, n (\%) & $19(2.9)$ & $9(5.5)$ & $12(2.2)$ & $16(5.8)$ \\
\hline $\mathrm{RR}(95 \% \mathrm{Cl})$ & 1.00 & 2.16 (1.02 to 4.68$)$ & 1.00 & 3.16 (1.52 to 6.58$)$ \\
\hline $\mathrm{p}$ Value & & 0.041 & & 0.002 \\
\hline Delayed overweight, n (\%) & $79(12.0)$ & $28(17.1)$ & $49(9.0)$ & $58(20.8)$ \\
\hline RR $(95 \% \mathrm{Cl})$ & 1.00 & 1.69 (1.15 to 2.49$)$ & 1.00 & 2.45 (1.73 to 3.46$)$ \\
\hline $\mathrm{p}$ Value & & 0.008 & & $<0.001$ \\
\hline Early transient overweight, $\mathrm{n}(\%)$ & 85 (12.9) & $27(16.4)$ & $73(13.5)$ & $39(14.0)$ \\
\hline RR $(95 \% \mathrm{Cl})$ & 1.00 & 1.35 (0.90 to 2.00$)$ & 1.00 & 1.25 (0.88 to 1.77$)$ \\
\hline $\mathrm{p}$ Value & & 0.144 & & 0.215 \\
\hline
\end{tabular}

*Model included the flowing variables: maternal smoking during pregnancy, maternal early pregnancy BMI, and sex.

tModel included the following variables: maternal smoking during pregnancy, maternal early pregnancy BMI, sex, birth weight, gestational age at birth, maternal age at delivery, duration of breastfeeding, maternal education and socioeconomic status.

BMI, Body Mass Index; n, number; RR, Risk ratio. 
Table 4 BMI z-score trajectories as predictors of asthma, $\mathrm{FEV}_{1} / \mathrm{FVC}$ ratio, and blood pressure at 18 years of age

\begin{tabular}{|c|c|c|c|c|}
\hline \multirow[b]{2}{*}{ Health outcomes at 18 years } & \multicolumn{4}{|c|}{ BMI z-score trajectories } \\
\hline & Normal & Early persistent obesity & Delayed overweight & Early transient overweight \\
\hline Asthma, \% (n/total) & $15.4(114 / 740)$ & $35.1(13 / 37)$ & $26.9(35 / 130)$ & $15.7(19 / 121)$ \\
\hline $\operatorname{RR}(95 \% \mathrm{Cl})^{*}$ & 1.00 (Reference) & 2.15 (1.33 to 3.49$)$ & 1.70 (1.22 to 2.38$)$ & 1.01 (0.65 to 1.58$)$ \\
\hline $\mathrm{p}$ Value & & 0.001 & 0.002 & 0.968 \\
\hline$F E V_{1} / F V C \%$, mean (SE) & $87.7(0.6)$ & $84.5(1.4)$ & $86.0(0.8)$ & $87.3(0.9)$ \\
\hline Mean difference $(95 \% \mathrm{Cl}) \dagger$ & 0.0 (Reference) & $-3.2(-6.0$ to -0.4$)$ & $-1.7(-3.2$ to -0.2$)$ & $-0.4(-2.1$ to 1.3$)$ \\
\hline $\mathrm{p}$ Value & & 0.027 & 0.025 & 0.637 \\
\hline Systolic BP (mm Hg), mean (SE) & $106.6(0.7)$ & $117.9(2.1)$ & $112.7(1.2)$ & $107.5(1.3)$ \\
\hline Mean difference $(95 \% \mathrm{Cl}) \dagger$ & 0.0 (Reference) & $11.3(7.1$ to 15.4$)$ & 6.1 (3.7 to 8.5$)$ & $0.9(-1.6$ to 3.5$)$ \\
\hline $\mathrm{p}$ Value & & $<0.001$ & $<0.001$ & 0.477 \\
\hline Diastolic BP (mm Hg), mean (SE) & $63.7(0.5)$ & $75.7(1.6)$ & $69.2(0.9)$ & $66.6(1.0)$ \\
\hline Mean difference $(95 \% \mathrm{Cl}) \dagger$ & 0.0 (Reference) & $12.0(8.9$ to 15.1$)$ & 5.5 (3.5 to 7.3$)$ & $2.9(0.9$ to 4.8$)$ \\
\hline$p$ Value & & $<0.001$ & $<0.001$ & 0.004 \\
\hline
\end{tabular}

${ }^{*}$ Adjusted for sex, smoking status at age 18 years, duration of breastfeeding, and socioeconomic status.

†Adjusted for sex, height at age 18 years, smoking status at age 18 years, duration of breastfeeding, and socioeconomic status.

$\mathrm{BMI}$, Body Mass Index; BP, blood pressure; $\mathrm{FEV}_{1}$, forced expiratory volume in one second; FVC, forced vital capacity; RR, risk ratio.

the normal trajectory, the magnitude of the increase in blood pressure (effect size) was larger for the early persistent obesity trajectory than the delayed overweight trajectory (table 4).

\section{Sensitivity analysis}

Our reported results that included 93 participants who selfreported their anthropometric measurements did not differ from the results based on participants with directly measured height and weight (see online supplementary figure S3, tables S2 and S3). Additionally, concurrent BMI at age 18 years showed associations with health outcomes (see online supplementary table S4). Additionally, controlling for concurrent BMI did not attenuate the association between BMI trajectories and asthma at 18 years (see online supplementary table S5 and online results II).

\section{DISCUSSION}

\section{Principle findings}

In this longitudinal study, we identified and characterised four BMI trajectories that spanned the first 18 years of life. The identified patterns of BMI trajectories in our study highlighted that the key 'change in path' occurred between ages 1 and 4 years (figure 1). Against that, between 4 and 10 years of age, the course of the BMI trajectories did not experience any directional changes. Therefore, our study demonstrates that the first 4 years of life is a critical developmental window where longterm developmental patterns of BMI might be established. However, this does not exclude that individual children who changed their lifestyle could experience a different trajectory. In support of a critical time window, our results also showed that average weight gain between 1 and 4 years was higher in the early persistent obesity and delayed overweight trajectories, in a gradient manner, compared to the normal trajectory (see online supplementary figure S2). Hence, weight gain and BMI trends need to be monitored during the first 4 years of life with focus on those at higher risk of later overweight obesity status.

Maternal smoking during pregnancy and maternal overweight in early pregnancy, increased an offspring's risk for being in the early persistent obesity and delayed overweight trajectories. In turn, morbid BMI trajectories predicted adverse health outcomes at 18 years of age. For instance, elevated risk of having asthma was associated with being in the early persistent obesity and delayed overweight trajectories. Reductions in the $\mathrm{FEV}_{1} /$ FVC ratio were also seen for these two morbid BMI trajectories. Of special note is that 18 -year-olds in the early persistent obesity trajectory, on average, had elevated systolic and diastolic blood pressure than the normal trajectory. Blood pressure parameters of children in the delayed overweight trajectory were also higher than the normal trajectory; however, the effect size was not as large as for those in the early persistent obesity trajectory. These strong and consistent associations between morbid BMI trajectories and different health outcomes emphasise the criticalness of considering age-of-onset, duration and intensity of adiposity.

\section{Comparison with previous studies}

An indispensable observation is that the patterns and numbers of BMI trajectories, in our and previous studies, across different populations and time-periods showed high resemblance (see online supplementary table S1). In almost all studies, in addition to a normal trajectory, a trajectory of chronically early obese children, and a trajectory of children gradually exceeding the overweight threshold late in childhood were identified (see online supplementary table S1). Finding common developmental trajectories across populations supports the validity and generalisability of our trajectories and may indicate shared predisposing factors that need further elucidation.

Associations between maternal prepregnancy/early pregnancy adiposity and offspring overweight obesity at different stages during childhood and adolescence have been reported previously. ${ }^{8}$ 37-39 Our observation of an association between early pregnancy overweight and early persistent obesity and delayed overweight trajectories in offspring suggests that maternal prenatal adiposity may have long-term consequences for overweight obesity risk in their offspring. The current state of knowledge does not provide clear biological understanding of this observed association; however, interplay between genetic factors, in utero priming, and the shared obesogenic environment could be relevant. $^{40}$ In agreement with our findings, a number of prior studies also identified maternal smoking during pregnancy as a risk factor for childhood overweight obesity. ${ }^{10} 3941$ A possible mechanism is that exposure to nicotine during fetal development results in an abnormal appetite regulation system, which ultimately regulates body weight and energy balance. ${ }^{41} 42$ 
However, we cannot exclude a shared overweight obesityinducing environment, including reduced physical activity ${ }^{10}$ and poor nutritional status ${ }^{43}$ that clusters with gestational smoking. Despite the clear deleterious effects, the prevalence of maternal prenatal adiposity and gestational smoking showed no declining trends in the last decades. ${ }^{44-47}$ Although of utmost importance, these risks are widely ignored in the current debate on how to prevent childhood overweight obesity.

Based on prior reports, the association between obesity and asthma among children and adolescents is weak and inconsistent. ${ }^{14}$ A drawback of the majority of prior studies is the use of BMI status at one time point as predictor of either concurrent (cross-sectional studies) or subsequent (longitudinal studies) asthma. This snapshot approach considers the 'intensity' of adiposity while ignoring the 'age-of-onset' and 'duration', which, we hypothesise, to be major factors in the development of asthma. In this study, we demonstrated that early persistent obesity and delayed overweight trajectories predicated the prevalence of asthma at 18 years of age. In support of the importance of adiposity 'duration', we did not observe any association between BMI trajectories and asthma at age 10 years (see online supplementary table S6); indicating that the duration, in addition to age-of-onset and intensity, of adiposity is an important factor for the association with asthma. The $\mathrm{FEV}_{1} / \mathrm{FVC}$ ratio, has been shown to be preserved in overweight obese adults ${ }^{48}$; however, inconclusive and conflicting findings in children and adolescents hamper existing literature. ${ }^{49}$ We found that being in the early persistent obesity and delayed overweight trajectories was associated with reduced $\mathrm{FEV}_{1} / \mathrm{FVC}$ ratio, which is in agreement with other reports. ${ }^{50} 51$ This observation that being obese for longer duration is associated with worse impairment in $\mathrm{FEV}_{1} / \mathrm{FVC}$ ratio is consistent with prior work that investigated associations of obesity duration and lung function parameters. ${ }^{16}$ Hence, results of this study demonstrate that accounting for the 'age-of-onset', 'duration', and 'intensity' of adiposity through BMI trajectories facilitated imparting strong and consistent associations of adiposity with asthma and lung function parameters among adolescents.

Markers of adiposity, including BMI, waist circumference, and fat mass, are associated with increased cardiovascular risk profiles among children and adolescents. ${ }^{12} 1352$ We sought, for the first time, to determine whether accounting for the developmental patterns of BMI could serve as a predictor of later blood pressure among adolescents. Systolic and diastolic blood pressures were noticeably elevated among the early persistent obesity trajectory in comparison to the normal trajectory. The delayed overweight trajectory experienced similar but lesser magnitude associations.

Although concurrent obesity at age 18 years was associated with health outcomes (see online supplementary table S4), disentangling the effects of BMI trajectories from concurrent BMI at age 18 years on health outcomes is difficult due to their interdependence (see online supplementary table S5 and online results II). Findings of this report highlight the importance of recognising the epidemic of overweight obesity in early life to overcome later adverse health-related consequences. Our study demonstrates that there are at least two opportunities to reduce later childhood and adolescence obesity. First, before and during pregnancy, by reducing smoking and adiposity in the mothers which, presumably, reduces the proportion of overweight obesity in offspring that is induced by these prenatal factors. Second, during early childhood by focusing on children with above-average weight gain between 1 and 4 years, in whom a focus on dietary and other lifestyle factors may prove beneficial.

\section{Strengths and limitations}

Using trajectory analysis allowed us to identify developmental patterns of BMI over age. However, inherent limitations of trajectory modelling include (1) determining the optimal number of latent trajectories/groups in the study population, which is a process guided by statistical fit indices and investigator's discretion that might overestimate or underestimate the true number of trajectories/groups and (2) the assignment of individuals to trajectories/groups is based on individuals' highest estimated group-membership probabilities; hence, the identified trajectories/groups should not be considered as the actual latent developmental categories, rather should be viewed as approximations of more complex developmental patterns. ${ }^{22}$

Although previous studies were able to identify BMI trajectories in restricted time windows of childhood and/or adolescence (see online supplementary table S1), our study has the advantage of prospectively covering the whole period from infancy to adolescence. The advantage of long-term follow-up is exemplified by finding strong associations between early persistent obesity and delayed overweight trajectories with asthma at 18 years, which was not clearly demonstrated in a study analysing eight European birth cohorts with follow-ups until 6 years of age. ${ }^{53}$ Additionally, the prospective repeated measurements of BMI add to the strengths of this study. A potential limitation of our study is that only four assessments of BMI (at ages 1, 4, 10 and 18 years) were used to obtain BMI developmental trajectories from 1 to 18 years of age. However, the comparability of the observed BMI trajectories patterns with previous studies (see online supplementary table S1) is an indicator of the validity and generalisability of our findings. The use of maternal early pregnancy BMI (measured $14 \pm 4$ weeks after conception) instead of prepregnancy BMI is a possible drawback of our study. Nevertheless, we speculate that expecting mothers have not gained much weight during the first trimester. In support, it has been suggested that self-reporting of prepregnancy weight is unreliable, while weight during the first trimester is representative of prepregnancy weight. ${ }^{54}$ Another possible limitation is the lack of information on gestational weight gain, which has been shown to predict offspring overweight obesity. ${ }^{8} 55$ Moreover, lack of data on maternal nutritional status during pregnancy and early childhood energy intake (diet) and energy expenditure (physical activity) are additional limitations to our study.

\section{CONCLUSIONS}

Our data showed that developmental trajectories of BMI during the period from 1 to 18 years of age are set in early childhood, supporting early origins of adiposity. Maternal smoking during pregnancy and early pregnancy overweight demonstrated longterm effects on offspring's propensity towards overweight obesity. Both these prenatal exposures are associated with increased risk for being in the early persistent obesity and delayed overweight trajectories which, in turn, predispose to various adverse health outcomes at 18 years of age. Increased risk of asthma, decreased $\mathrm{FEV}_{1} / \mathrm{FVC}$ ratio, and elevated blood pressure were associated with these two morbid BMI trajectories. The importance of BMI trajectories, abridging the 'age-of-onset', 'duration', and 'intensity' of adiposity, is demonstrated through their predictive ability. Our study demonstrates the criticalness of preventing overweight obesity and smoking in women of childbearing age, and focusing public health preventative efforts towards early childhood. The prenatal and early childhood periods should be regarded as crucial windows of opportunity to combat the obesity epidemic. 


\section{What is already known on this subject}

- A limited number of longitudinal studies have identified developmental trajectories of Body Mass Index (BMI) in childhood and/or adolescence; however, none have covered the period from early infancy to late adolescence and also investigated prenatal risk factors and health consequences of such BMI trajectories.

- Although maternal gestational smoking and prenatal adiposity have shown associations with offspring's overweight obesity, knowledge on whether these prenatal exposures influence the long-term developmental patterns of $\mathrm{BMI}$ in offspring is lacking.

- BMI measured at one time-point during childhood and/or adolescence have been associated with adverse health-related outcomes, but whether accounting for the age-of-onset, duration and intensity of adiposity through BMI trajectories serve as a better predictor of later morbidity remains unclear.

\section{REFERENCES}

1 Finucane MM, Stevens GA, Cowan MJ, et al. National, regional, and global trends in body-mass index since 1980: systematic analysis of health examination surveys and epidemiological studies with 960 country-years and 9.1 million participants. Lancet 2011;377:557-67.

2 Withrow D, Alter DA. The economic burden of obesity worldwide: a systematic review of the direct costs of obesity. Obes Rev 2011:12:131-41.

3 Adair LS. Child and adolescent obesity: epidemiology and developmental perspectives. Physiol Behav 2008;94:8-16.

4 Park MH, Falconer C, Viner RM, et al. The impact of childhood obesity on morbidity and mortality in adulthood: a systematic review. Obes Rev 2012;13:985-1000.

5 Chinthapalli K. A third of children finishing primary school in England are overweight or obese. BMJ 2012;345:e8488.

6 Weng SF, Redsell SA, Swift JA, et al. Systematic review and meta-analyses of risk factors for childhood overweight identifiable during infancy. Arch Dis Child 2012:97:1019-26.

7 Brisbois TD, Farmer AP, McCargar LJ. Early markers of adult obesity: a review. Obes Rev 2012:13:347-67.

8 Gaillard R, Durmus B, Hofman A, et al. Risk factors and outcomes of maternal obesity and excessive weight gain during pregnancy. Obesity (Silver Spring) 2013:21:1046-55.

9 Whitaker RC. Predicting preschooler obesity at birth: The role of maternal obesity in early pregnancy. Pediatrics 2004;114:E29-36.

10 Oken E, Levitan EB, Gillman MW. Maternal smoking during pregnancy and child overweight: systematic review and meta-analysis. Int J Obes (Lond) 2008;32:201-10.

11 Al Mamun A, Lawlor DA, Alati $\mathrm{R}$, et al. Does maternal smoking during pregnancy have a direct effect on future offspring obesity? Evidence from a prospective birth cohort study. Am J Epidemiol 2006;164:317-25.

12 Friedemann C, Heneghan C, Mahtani K, et al. Cardiovascular disease risk in healthy children and its association with body mass index: systematic review and meta-analysis. BMJ 2012;345:e4759.

13 Lawlor DA, Benfield L, Logue J, et al. Association between general and central adiposity in childhood, and change in these, with cardiovascular risk factors in adolescence: prospective cohort study. BMJ 2010;341:c6224.

14 Papoutsakis C, Priftis KN, Drakouli M, et al. Childhood overweight/obesity and asthma: is there a link? A systematic review of recent epidemiologic evidence. J Acad Nutr Diet 2013:113:77-105.

15 Boulet LP. Asthma and obesity. Clin Exp Allergy 2013;43:8-21.

16 Santamaria F, Montella S, Greco L, et al. Obesity duration is associated to pulmonary function impairment in obese subjects. Obesity (Silver Spring) 2011;19:1623-8.

17 de Koning L, Hu FB. Commentary: Obesity-years - a new metric to measure health effects of obesity. Int J Epidemiol 2011;40:996-7.

18 Abdullah A, Wolfe R, Mannan $\mathrm{H}$, et al. Epidemiologic merit of obese-years, the combination of degree and duration of obesity. Am J Epidemiol 2012;176: 99-107.

19 Abdullah A, Wolfe R, Stoelwinder JU, et al. The number of years lived with obesity and the risk of all-cause and cause-specific mortality. Int J Epidemiol 2011:40:985-96.

20 Reis JP, Loria CM, Lewis CE, et al. Association between duration of overall and abdominal obesity beginning in young adulthood and coronary artery calcification in middle age. JAMA 2013:310:280-8

Acknowledgements We would like to acknowledge the help of all the staff at The David Hide Asthma and Allergy Research Centre in undertaking the 18-year and previous assessments of 1989 Isle of Wight birth cohort. We would also like to acknowledge the help of the participants and their families who have helped us with this project over the last two decades.

Contributors Conceived and designed the study: $\mathrm{AHZ}, \mathrm{WK}$ and SHA. Analysed and interpreted the data: AHZ. Interpretation of results: WK, SHA, HZ and RJK. Drafted the manuscript: AHZ. Involved in the acquisition of data: SHA, WK, RJK and HZ. All authors critically revised the manuscript for important intellectual content. The manuscript has been read and approved by all authors.

Funding The 10-year follow-up of this study was funded by National Asthma Campaign, UK (Grant No 364) and the 18-year follow-up by the National Heart, Lung, and Blood Institute, R01 HL082925-01 (PI: SHA). The analysis was in part supported by the National Institute of Allergy and Infectious Diseases under Award Number R01 Al091905-01 (PI: WK) and by Memphis Research Consortium.

\section{Competing interests None.}

Ethics approval Obtained from the Isle of Wight Local Research Ethics Committee (now named the National Research Ethics Service, NRES Committee South CentralSouthampton B) at recruitment and for the subsequent follow-ups (06/Q1701/34).

Provenance and peer review Not commissioned; externally peer reviewed.

Open Access This is an Open Access article distributed in accordance with the Creative Commons Attribution Non Commercial (CC BY-NC 3.0) license, which permits others to distribute, remix, adapt, build upon this work non-commercially, and license their derivative works on different terms, provided the original work is properly cited and the use is non-commercial. See: http://creativecommons.org/ licenses/by-nc/3.0/
21 Sackmann R, Wingens M. Social dynamics of the life course: transitions, institutions, and interrelations. Hawthorne, NY: Aldine de Gruyter, 2003.

22 Nagin DS, Odgers CL. Group-based trajectory modeling in clinical research. Annu Rev Clin Psychol 2010;6:109-38.

23 Mustillo S, Worthman C, Erkanli A, et al. Obesity and psychiatric disorder: developmental trajectories. Pediatrics 2003:111:851-9.

24 Li C, Goran MI, Kaur H, et al. Developmental trajectories of overweight during childhood: role of early life factors. Obesity (Silver Spring) 2007;15:760-71.

25 Ventura AK, Loken E, Birch LL. Developmental trajectories of girls' BMI across childhood and adolescence. Obesity (Silver Spring) 2009:17:2067-74.

26 Nonnemaker JM, Morgan-Lopez AA, Pais JM, et al. Youth BMI trajectories: evidence from the NLSY97. Obesity (Silver Spring) 2009;17:1274-80.

27 Magee CA, Caputi $P$, Iverson DC. Identification of distinct body mass index trajectories in Australian children. Pediatr Obes 2013;8:189-98.

28 Pryor LE, Tremblay RE, Boivin M, et al. Developmental trajectories of body mass index in early childhood and their risk factors: an 8-year longitudinal study. Arch Pediatr Adolesc Med 2011;165:906-12.

29 Haga C, Kondo N, Suzuki K, et al. Developmental trajectories of body mass index among Japanese children and impact of maternal factors during pregnancy. PLOS One 2012;7:e51896.

30 Huang DY, Lanza HI, Wright-Volel K, et al. Developmental trajectories of childhood obesity and risk behaviors in adolescence. J Adolesc 2013:36:139-48.

31 Cole TJ, Bellizzi MC, Flegal KM, et al. Establishing a standard definition for child overweight and obesity worldwide: international survey. BMJ 2000;320:1240-3.

32 WHO Multicentre Growth Reference Study Group. WHO Child Growth Standards based on length/height, weight and age. Acta Paediatrica Suppl 2006:450:76-85. 
33 Asher MI, Keil U, Anderson HR, et al. International Study of Asthma and Allergies in Childhood (ISAAC): rationale and methods. Eur Respir J 1995;8:483-91.

34 American Thoracic Society. Standardization of Spirometry, 1994 Update. Am J Respir Crit Care Med 1995;152:1107-36.

35 Nagin DS. Analyzing developmental trajectories: a semiparametric, group-based approach. Psychol Methods 1999;4:139-57.

36 Jones BL, Nagin DS, Roeder K. A SAS Procedure Based on Mixture Models for Estimating Developmental Trajectories. Sociolog Methods Res 2001;29:374-93.

37 Linabery AM, Nahhas RW, Johnson W, et al. Stronger influence of maternal than paternal obesity on infant and early childhood body mass index: the Fels Longitudinal Study. Pediatr Obes 2013;8:159-69.

38 Oken E. Maternal and child obesity: the causal link. Obstet Gynecol Clin North Am 2009;36:361-77, ix-x.

39 Gillman MW, Ludwig DS. How early should obesity prevention start? N Engl J Med 2013;369:2173-5.

40 Tounian P. Programming towards childhood obesity. Ann Nutr Metab 2011;58 (Suppl 2):30-41.

41 Behl M, Rao D, Aagaard K, et al. Evaluation of the association between materna smoking, childhood obesity, and metabolic disorders: a national toxicology program workshop review. Environ Health Perspect 2013;121:170-80.

42 Bruin JE, Gerstein HC, Holloway AC. Long-term consequences of fetal and neonatal nicotine exposure: a critical review. Toxicol Sci 2010;116:364-74.

43 Duarte-Salles T, Mendez MA, Pessoa V, et al. Smoking during pregnancy is associated with higher dietary intake of polycyclic aromatic hydrocarbons and poor diet quality. Public Health Nutr 2010;13:2034-43.

44 Owen L, McNeill A, Callum C. Trends in smoking during pregnancy in England, 1992-7: quota sampling surveys. BMJ 1998;317:728
45 Ward C, Lewis S, Coleman T. Prevalence of maternal smoking and environmental tobacco smoke exposure during pregnancy and impact on birth weight: retrospective study using Millennium Cohort. BMC Public Health 2007;7:81.

46 Fisher SC, Kim SY, Sharma AJ, et al. Is obesity still increasing among pregnant women? Prepregnancy obesity trends in 20 states, 2003-2009. Prev Med 2013;56:372-8

47 Heslehurst N, Rankin J, Wilkinson JR, et al. A nationally representative study of maternal obesity in England, UK: trends in incidence and demographic inequalities in 619323 births, 1989-2007. Int J Obes (Lond) 2010;34:420-8.

48 Littleton SW. Impact of obesity on respiratory function. Respirology 2012;17:43-9.

49 Santamaria F, Montella S, Pietrobelli A. Obesity and pulmonary disease: unanswered questions. Obes $\operatorname{Rev} 2012 ; 13: 822-33$.

50 Davidson WJ, Mackenzie-Rife KA, Witmans MB, et al. Obesity negatively impacts lung function in children and adolescents. Pediatr Pulmonol Published Online First: 25 Oct 2013. doi:10.1002/ppul.22915

51 Tantisira KG, Litonjua AA, Weiss ST, et al. Association of body mass with pulmonary function in the Childhood Asthma Management Program (CAMP). Thorax 2003;58:1036-41.

52 Falaschetti $\mathrm{E}$, Hingorani $\mathrm{AD}$, Jones $\mathrm{A}$, et al. Adiposity and cardiovascular risk factors in a large contemporary population of pre-pubertal children. Eur Heart $J$ 2010:31:3063-72.

53 Rzehak P, Wijga AH, Keil T, et al. Body mass index trajectory classes and incident asthma in childhood: results from 8 European Birth Cohorts-a Global Allergy and Asthma European Network initiative. J Allergy Clin Immunol 2013;131:1528-36.

54 Harris HE, Ellison GT. Practical approaches for estimating prepregnant body weight. J Nurse Midwifery 1998;43:97-101.

55 Ludwig DS, Rouse HL, Currie J. Pregnancy weight gain and childhood body weight: a within-family comparison. PLoS Med 2013;10:e1001521. 